\title{
Ureia revestida e o crescimento do cafeeiro arábica
}

Coated urea and the growth of arabica coffee

Urea revestida y el crecimiento del café arábigo

Jorge Luiz Abranches

Engenheiro Agrônomo, Mestre, UNESP, Brasil jorgeabranches@bauru.sp.gov.br

Rogério Peres Soratto Engenheiro Agrônomo, Professor Doutor, UNESP, Brasil soratto@fca.unesp.br

Marcos José Perdoná Engenheiro Agrônomo, Doutor, UNESP, Brasil marcosperdona@apta.sp.gov.br 


\section{RESUMO}

Novas tecnologias são utilizadas na tentativa de reduzir as perdas do nitrogênio utilizado na agricultura. 0 trabalho objetivou avaliar o crescimento do cafeeiro arábica em função do uso de ureia revestida e convencional, em diferentes doses. O experimento foi conduzido no município de Bauru-SP, entre os anos de 2014 a 2016 . 0 delineamento foi o de blocos casualizados, em esquema fatorial $2 \times 3+1$, com seis repetições. Os tratamentos consistiram de duas fontes (ureia revestida Kimcoat $N^{\circledR}$ e ureia convencional), três doses de N (150, 300 e 600 kg ha ${ }^{1}$ ) e uma testemunha (sem aplicação de N). O uso da adubação nitrogenada favoreceu o crescimento dos cafeeiros, contudo, quando comparada à ureia convencional, a ureia revestida não promoveu maior comprimento dos ramos plagiotrópicos ou aumentou no número de nós nos ramos dos cafeeiros.

PALAVRAS-CHAVE: Coffea arabica. Nitrogênio. Produtividade de grãos. Liberação controlada.

\section{ABSTRACT}

New technologies are used in an attempt to reduce the losses of nitrogen used in agriculture. The objective of this work was to evaluate the growth of arabica coffee as a function of the use of coated and conventional urea in different doses. The experiment was conducted in the municipality of Bauru-SP between 2014 and 2016. The design was randomized blocks, in a $2 \times 3+1$ factorial scheme, with six replications. The treatments consisted of two sources (Kimcoat $\mathrm{N}^{\circledR}$ coated urea and conventional urea), three $\mathrm{N}$ doses (150, 300 and $600 \mathrm{~kg} \mathrm{ha}^{-1}$ ) and one control (without $\mathrm{N}$ application). The use of nitrogen fertilization favored the growth of coffee plants, however, when compared to conventional urea, coated urea did not promote longer plagiotropic tree lengths or increased the number of nodes in the coffee tree branches.

KEYWORDS: Coffea arabica. Nitrogen. Grain productivity. Controlled release.

\section{RESUMEN}

Las nuevas tecnologías se utilizan para reducir las pérdidas de nitrógeno utilizadas en la agricultura. El trabajo objetivó evaluar el crecimiento del café arábigo en función del uso de urea revestida y convencional, en diferentes dosis. El experimento fue conducido en el municipio de Bauru-SP, entre los años 2014 a 2016. El delineamiento fue el de bloques casualizados, en esquema factorial $2 \times 3+1$, con seis repeticiones. Los tratamientos consistieron de dos fuentes (urea recubierta de Kimcoat $N^{\circ}$ y urea convencional), tres dosis de $N\left(150,300\right.$ y $600 \mathrm{~kg} \mathrm{ha}^{-1}$ ) y un testigo (sin aplicación de N). El uso de la fertilización nitrogenada favoreció el crecimiento de los cafetos, sin embargo, cuando se comparó con la urea convencional, la urea revestida no promovió mayor longitud de las ramas plagiotrópicas o aumentó en el número de nudos en las ramas de los cafetos.

PALABRAS CLAVE: Coffea arabica. Nitrógeno. Productividad de granos. Liberación controlada. 


\section{INTRODUÇÃO}

Considerando suas perdas, práticas de manejo da adubação nitrogenada do cafeeiro ainda demandam muitos estudos e avanços (FENILLI, 2006). O nitrogênio (N) é o elemento que, na grande maioria das vezes, proporciona os maiores efeitos no aumento da produtividade de grãos, tendo importância na expansão da área foliar, crescimento vegetativo, formação dos botões florais, granação dos frutos e na produtividade das plantas. Contudo, o manejo da adubação com $\mathrm{N}$ é tido como um dos mais difíceis, devido ao dinamismo desse nutriente no solo, das inúmeras reações químicas que ocorrem no campo, do envolvimento dos fatores climáticos e, principalmente, da relação com a disponibilidade hídrica (CANTARELLA; DUARTE, 2004). Dessa forma, a maior parte do $\mathrm{N}$ aplicado pode ser perdido no sistema solo-planta, por processos de volatilização, lixiviação, desnitrificação e erosão. Outra parte permanece no solo na forma orgânica, assim, apenas uma parte do $\mathrm{N}$ mineral aplicado é absorvido pelas plantas (LARA CABEZAS et al., 2000; VARGAS, 2010).

A ureia a principal fonte de $\mathrm{N}$ usado no Brasil. Apesar de apresentar elevada concentração de $\mathrm{N}$ e menor preço desse elemento por unidade (MATIELLO, et al., 2010), ela apresenta inúmeras limitações, especialmente quando utilizada em cobertura e em condições climáticas inadequadas, por conta das perdas por volatilização. Considerando-se o potencial de perdas do $\mathrm{N}$, recomenda-se que a maior parte da aplicação do fertilizante nitrogenado seja realizada parceladamente em coberturas (BAYER; FONTOURA, 2006). Entretanto, a aplicação parcelada exige maior número de operações, o que acaba por aumentar o custo de produção.

Uma das formas de minimizar as perdas desse fertilizante seria o desenvolvimento de novas tecnologias para aumentar a eficiência do uso do N (GUELFI, 2017). Entre as diversas soluções apresentadas para esses problemas, teoricamente, o uso de polímeros no revestimento da ureia apresenta bom potencial (ABRANCHES et al., 2014).

A ureia revestida é recoberta por um produto líquido formado por polímeros com alta densidade de cargas elétricas que tem como objetivo proteger a ureia, principalmente contra a volatilização, melhorando a eficiência de uso do N (REIS JÚNIOR, 2007). Essa tecnologia propõe que o encapsulamento de fertilizantes forme uma película protetora não afetando a disponibilização do nutriente para a planta e impedindo que os diversos fatores causadores de perdas de nutrientes atuem (SILVA et al., 2012).

Nesse sentido, é possível que o uso da ureia revestida seja uma boa opção de redução de perdas de $\mathrm{N}$, possibilitando maior absorção do nutriente pelo cafeeiro e maximizando a eficiência da adubação, com maiores produtividades e menor custo. Entretanto, observa-se que os trabalhos desenvolvidos, até o momento, estudaram o uso dessa tecnologia em culturas anuais, especialmente a do milho, e que, apesar do Brasil ser o maior produtor e exportador de café do mundo, raros trabalhos foram realizados com essa cultura, tornando difícil qualquer conclusão sobre as reais vantagens dessa tecnologia nos cafezais. O presente trabalho avaliou o crescimento vegetativo do cafeeiro para aferir se houve maior eficiência da ureia revestida no crescimento do cafeeiro, em comparação à ureia convencional.

\section{METODOLOGIA}

O experimento foi instalado em outubro de 2014 , no município de Bauru, SP $\left(22^{\circ} 14^{\prime} \mathrm{S}, 49^{\circ}\right.$ 11 'W, a 576 m de altitude) em uma lavoura não irrigada, cultivar Mundo Novo IAC 388-17-1, no espaçamento de $4,0 \times 0,80 \mathrm{~m}$, com quatro anos de plantio.

O solo do local foi caracterizado como sendo um Latossolo Vermelho Amarelo distrófico (Santos et al., 2013). Antes da instalação do experimento (agosto de 2014) foi realizada a caracterização química e granulométrica do solo, na faixa de adubação (projeção da copa). $\mathrm{Na}$ camada de 0-20 cm de profundidade as características eram: $\mathrm{pH}$ em $\mathrm{CaCl}_{2}$ de 5,4; $9 \mathrm{~g} \mathrm{dm}^{3}$ de 
MO; $108 \mathrm{mg} \mathrm{dm}^{3}$ de $\mathrm{P}_{\text {resina }} ; 2,2 ; 22,10,17 \mathrm{mmolc} \mathrm{dm}^{-3}$ de $\mathrm{K}, \mathrm{Ca}, \mathrm{Mg}$ e H+Al, respectivamente; $22 \mathrm{mg} \mathrm{dm}^{3}$ de S-SO ${ }_{4}^{2-}$; saturação por bases de $68 \%$; $96 \%$ de areia; $1 \%$ de silte; e $3 \%$ de argila. Na profundidade de 20-40 cm, o solo apresentava: $\mathrm{pH} \mathrm{em} \mathrm{CaCl}_{2}$ de 4,6; $6 \mathrm{~g} \mathrm{dm}^{3}$ de $\mathrm{MO} ; 100 \mathrm{mg}$ $\mathrm{dm}^{3}$ de $\mathrm{P}_{\text {resina }} ; 2,3 ; 12,4,21$ mmolc $\mathrm{dm}^{-3}$ de $\mathrm{K}, \mathrm{Ca}, \mathrm{Mg}$ e H+Al, respectivamente; $42 \mathrm{mg} \mathrm{dm}^{3}$ de S $\mathrm{S} \mathrm{SO}_{4}{ }^{2-}$; saturação por bases de $47 \%$; $92 \%$ de areia; $2 \%$ de silte; e $6 \%$ de argila.

Segundo a classificação de Koeppen, o clima da região é Aw, tropical, com estação seca no inverno e verão chuvoso, temperatura média anual de $22,6{ }^{\circ} \mathrm{C}$ e regime pluviométrico anual em torno de $1.331 \mathrm{~mm}$ (CEPAGRI, 2017). Os dados climáticos do período experimental, de acordo com o Instituto de Pesquisas Meteorológicas (IPMET, 2017), estão apresentados na Tabela 1.

Tabela 1. Temperaturas médias do ar e precipitações pluviais mensais, no período de condução do experimento, de agosto de 2014 a junho de 2017.

\begin{tabular}{|c|c|c|c|c|c|c|c|c|}
\hline \multirow{2}{*}{ Mês } & \multicolumn{4}{|c|}{ Temperatura média do $\operatorname{ar}\left({ }^{\circ} \mathrm{C}\right)$} & \multicolumn{4}{|c|}{ Precipitação pluvial (mm) } \\
\hline & 2014 & 2015 & 2016 & 2017 & 2014 & 2015 & 2016 & 2017 \\
\hline Janeiro & - & 27,5 & 26,1 & 25,0 & - & 182,4 & 380,2 & 462,0 \\
\hline Fevereiro & - & 25,5 & 27,5 & 26,2 & - & 134,1 & 351,3 & 137,9 \\
\hline Março & - & 24,5 & 25,1 & 24,8 & - & 251,5 & 118,9 & 135,9 \\
\hline Abril & - & 23,7 & 25,2 & 22,6 & - & 46,7 & 37,8 & 119,1 \\
\hline Maio & - & 20,9 & 19,7 & 21,0 & - & 125,2 & 110,2 & 218,7 \\
\hline Junho & - & 20,7 & 18,1 & 19,2 & - & 0,0 & 94,0 & 22,4 \\
\hline Julho & - & 20,3 & 19,5 & - & - & 88,1 & 9,1 & - \\
\hline Agosto & 21,7 & 22,5 & 20,7 & - & 22,4 & 21,6 & 61,7 & - \\
\hline Setembro & 23,1 & 24,1 & 21,3 & - & 125,0 & 220,2 & 24,6 & - \\
\hline Outubro & 25,0 & 25,3 & 23,3 & - & 37,3 & 123,4 & 103,6 & - \\
\hline Novembro & 24,8 & 25,0 & 23,8 & - & 116,0 & 260,1 & 91,2 & - \\
\hline Dezembro & 25,1 & 25,9 & 25,0 & - & 257,0 & 259,8 & 143,8 & - \\
\hline
\end{tabular}

O delineamento experimental foi de blocos ao acaso, em esquema fatorial $2 \times 3+1$ com seis repetições. Os tratamentos consistiam de duas fontes de $\mathrm{N}$ (ureia convencional sem revestimento e ureia com revestimento Kimcoat $\left.N^{\circ}\right)$, três doses de $N\left(150,300\right.$ e $600 \mathrm{~kg} \mathrm{ha}^{-1}$ de N) e uma testemunha (sem aplicação de N). Os grânulos da ureia revestida continham três camadas de um polímero de alta densidade de carga (NutriSphere- $\mathrm{N}^{\circ}$ ). Cada parcela foi composta por sete plantas consecutivas de uma mesma fileira, totalizando $22,4 \mathrm{~m}^{2}$. Os fertilizantes foram aplicados manualmente na faixa de projeção da copa das plantas, sem incorporação e parcelados em três vezes, com intervalos de 45 dias, entre os meses de outubro a março de cada ano.

Antes da implantação do experimento, as adubações eram realizadas de maneira igualitária em todo o talhão, de acordo com os critérios do produtor. A partir da implantação do experimento todas as adubações foram calculadas seguindo recomendações para a faixa de produtividade esperada de $2.400-3.600 \mathrm{~kg} \mathrm{ha}^{-1}$ de café beneficiado (RAIJ et al., 1997). Assim, além dos tratamentos, nas mesmas datas também foram aplicados em todas as parcelas: 200 $\mathrm{kg} \mathrm{ha}^{-1}$ ano $^{-1}$ de $\mathrm{K}_{2} \mathrm{O}$ e $80 \mathrm{~kg} \mathrm{ha}^{-1}$ ano $^{-1}$ de $\mathrm{P}_{2} \mathrm{O}_{5}$. Para atender as demandas com micronutrientes, em janeiro e março de cada ano agrícola, foram aplicados via foliar: sulfato de magnésio $(2 \mathrm{~kg}$ $\left.\mathrm{ha}^{-1}\right)$, ácido bórico $\left(1,5 \mathrm{~kg} \mathrm{ha}^{-1}\right)$, sulfato de manganês $\left(2 \mathrm{~kg} \mathrm{ha}^{-1}\right)$, sulfato de zinco $\left(2 \mathrm{~kg} \mathrm{ha}^{-1}\right) \mathrm{e}$ sulfato de cobre $\left(3 \mathrm{~kg} \mathrm{ha}^{-1}\right)$. Para o controle de plantas daninhas, foram realizadas roçadas 
mecanizadas nas entrelinhas e aplicação do herbicida glifosato (720 $\mathrm{g} \mathrm{ha}^{-1}$ do i.a.), em uma faixa de $1,5 \mathrm{~m}$ de cada lado, a partir do tronco das plantas.

O manejo fitossanitário foi feito mediante a aplicação, via solo, de inseticida e fungicida tiametoxam (300 $\mathrm{g} \mathrm{ha}^{-1}$ do i.a.) + ciproconazol (300 $\mathrm{g} \mathrm{ha}^{-1}$ do i.a.) e de pulverizações foliares dos fungicidas tebuconazol (200 $\mathrm{g} \mathrm{ha}^{-1}$ do i.a.), piraclostrobina + epoxiconazol ( $274,5 \mathrm{~g} \mathrm{ha}^{-1} \mathrm{do}$ i.a.) e oxicloreto de cobre $\left(2,5 \mathrm{~kg} \mathrm{ha}^{-1}\right.$ do i.a.).

Em outubro de 2014, antes do início da aplicação dos tratamentos, realizou-se a caracterização das plantas de todas as parcelas, medindo-se o comprimento de 3 ramos plagiotrópico e o número de nós dos mesmos, de 3 plantas centrais de cada parcela. Nos meses de março e outubro de 2015 e março de 2016, realizou-se novas avaliações. Os resultados foram submetidos à análise de variância através do programa estatístico SISVAR. As médias das fontes, no esquema fatorial, foram comparadas pelo teste $t$ (DMS) a $5 \%$ de probabilidade. Os efeitos das doses de $\mathrm{N}$ foram avaliados por análise de regressão e, para esse propósito, a testemunha (sem aplicação de N) foi considerada como dose zero, adotando-se como critério, para escolha do modelo matemático, a magnitude dos coeficientes de regressão, significativos a $5 \%$ de probabilidade, pelo teste $\mathrm{F}$.

\section{RESULTADOS}

O número de nós nos ramos plagiotrópicos da parte superior da planta, localizado imediatamente acima a lignificação do ramo ortotrópico foi influenciado pelas doses de $\mathrm{N}$, mas não pela fonte, ou pela interação entre os fatores dose e fonte, nas três avaliações realizadas (Tabela 2).

Tabela 02. Número de nós no ramo plagiotrópico da planta de café arábica em função de fontes e doses de nitrogênio, em diferentes épocas de avaliação nos anos agrícolas 2014/15 e 2015/16.

\begin{tabular}{|c|c|c|c|c|}
\hline \multirow{2}{*}{ Tratamento } & \multicolumn{4}{|c|}{ Época de avaliação } \\
\hline & Out.2014 & Mar.2015 & Out. 2015 & Mar. 2016 \\
\hline & - & -1 & $\left.\mathrm{mo}^{-1}\right)$ & \\
\hline \multicolumn{5}{|l|}{ Fonte de $\mathrm{N}$} \\
\hline Ureia comum & $7,0 a^{(2)}$ & $14,1 \mathrm{a}$ & $19,8 a$ & $24,8 a$ \\
\hline Ureia revestida & $6,9 a$ & $14,2 a$ & $19,9 a$ & $25,3 a$ \\
\hline \multicolumn{5}{|l|}{ Dose de N $\left(\mathrm{kg} \mathrm{ha}^{-1}\right)$} \\
\hline 0 & 7,3 & 12,6 & 16,4 & 20,8 \\
\hline 150 & 7,1 & 14,2 & 19,5 & 23,8 \\
\hline 300 & 6,9 & 13,9 & 19,5 & 24,7 \\
\hline 600 & 6,9 & 14,3 & 20,4 & 26,5 \\
\hline Regressão & ns & (3) & (4) & (5) \\
\hline Interação D×F $\mathrm{F}^{(1)}$ & 0,450 & 0,143 & 0,814 & 0,547 \\
\hline $\mathrm{CV}(\%)$ & 8,7 & 4,7 & 7,7 & 6,6 \\
\hline
\end{tabular}

${ }^{(1)}$ Interação considerando apenas o fatorial 2 fontes $\times 3$ doses. ${ }^{(2)}$ Médias seguidas por letras distintas, na coluna dentro do fator fonte de $\mathrm{N}$, diferem entre si pelo teste $\mathrm{F}$ a $5 \%$ de probabilidade, na análise considerando apenas o fatorial 2 fontes $\times 3$ doses. ${ }^{(3)} y=12,798+0,007469 * * x-0,000008^{* *} x^{2} R^{2}=0,78 ;{ }^{(4)} y=16,671+0,016757^{* *} x-$ $0,000018^{* *} x^{2} R^{2}=0,90 ;{ }^{(5)} y=20,948+0,018361 * * x-0,000015^{* *} x^{2} R^{2}=0,98 . n s, *$ e ** são não-significativos e significativos a $5 \%$ e $1 \%$ de probabilidade, respectivamente, pelo teste $\mathrm{F}$.

Nas três avaliações realizadas, entre de março de 2015 a março de 2016, a aplicação de doses crescentes de $\mathrm{N}$ promoveu efeitos quadráticos no número de nós, com incremento até as 
doses estimadas de 467, 466 e $612 \mathrm{~kg} \mathrm{ha}^{-1}$ de $\mathrm{N}$, respectivamente (Tabela 2). Resultados semelhantes, mas com doses ideais diferentes, foram encontrados por Nazareno et al. (2003), trabalhando com a cultivar Rubi MG 1192 e Parecido (2016), com a cultivar Catuaí Vermelho IAC 99. Contudo, Vilela (2014), observou que diferentes cultivares de café com idades distintas, exigem níveis de nutrição diferenciados, durante o ano e a cada ano, justificando essas diferenças. Além disso, a baixa disponibilidade de matéria orgânica e o baixo teor de argila no solo do presente estudo, favoreceram o menor aproveitamento do $\mathrm{N}$.

$\mathrm{Na}$ avaliação realizada em março de 2015, independente da fonte utilizada, as doses de 150 , 300 e $600 \mathrm{~kg} \mathrm{ha}^{-1}$ de $\mathrm{N}$ promoveram incrementos de 7,1; 6,8 e 7,2 nós, respectivamente, em relação ao número médio de nós, enquanto que na testemunha, sem a aplicação de $\mathrm{N}$, o incremento foi de 5,5 nós (Tabela 2). No período de março de 2015 a março de 2016, as doses de 300 e $600 \mathrm{~kg} \mathrm{ha}^{-1}$ de $\mathrm{N}$, independentemente da fonte, promoveram aumento de 10,8 e 12,2 nós, respectivamente, enquanto na testemunha, sem aplicação de $\mathrm{N}$, o número médio de nós incrementado foi de 8,2 (Tabela 2). Contudo, em nenhum momento foi verificado influência da fonte, ou pela interação entre os fatores dose e fonte. Lima et al. (2016), em Araguari-MG, testando ureia revestida, na cultura do café arábica irrigado, também observaram efeitos positivos no número de nós pelo uso de $\mathrm{N}$ em relação à testemunha. No período avaliado de outubro de 2012 até maio de 2013, nas doses de 210 e $300 \mathrm{~kg} \mathrm{ha}^{-1}$ de $\mathrm{N}$, na forma de ureia convencional, verificaram aumento médio de 10,9 nós. Já com a aplicação de ureia revestida, nas mesmas doses, observaram aumento médio de 9,3 nós. No período de outubro de 2013 a maio de 2014, para as mesmas doses de N, a ureia revestida promoveu aumento médio de 9,8 nós, enquanto que, com a ureia convencional repetiu-se o mesmo incremento de 10,9 nós. $\mathrm{E}$, assim como no presente trabalho, Lima et al. (2016) concluíram que não houve diferença entre a ureia revestida e a convencional no número de nós no ramo plagiotrópico da planta de café. Assim como para o número de nós, em todas as avaliações, as doses de $\mathrm{N}$ influenciaram positivamente o comprimento dos ramos plagiotrópicos. Os efeitos da aplicação das doses crescentes de $\mathrm{N}$ foram quadráticos para as avaliações de março de 2015, outubro de 2015 e março de 2016, com incrementos até as doses estimadas de 424, 417 e $443 \mathrm{~kg}$ de $\mathrm{N}^{-1}$, respectivamente (Tabela 3). 
Tabela 03. Comprimento do ramo plagiotrópico da planta de café arábica em função de fontes e doses de nitrogênio, em diferentes épocas de avaliação nos anos agrícolas 2014/15, 2015/16 e 2016/17.

\begin{tabular}{|c|c|c|c|c|}
\hline \multirow{2}{*}{ Tratamento } & \multicolumn{4}{|c|}{ Época de avaliação } \\
\hline & Out.2014 & Mar.2015 & Out. 2015 & Mar. 2016 \\
\hline \multirow{2}{*}{\multicolumn{5}{|c|}{ Fonte de $\mathrm{N}$}} \\
\hline & & & & \\
\hline Ureia comum & $22,5 a^{(2)}$ & $42,4 a$ & $53,3 a$ & $63,1 \mathrm{a}$ \\
\hline Ureia revestida & $22,2 a$ & $43,1 a$ & $52,8 a$ & $62,8 a$ \\
\hline \multicolumn{5}{|l|}{ Dose de N (kg ha $\left.{ }^{-1}\right)$} \\
\hline 0 & 23,2 & 35,5 & 40,7 & 47,9 \\
\hline 150 & 22,9 & 42,4 & 51,8 & 60,6 \\
\hline 300 & 22,4 & 42,7 & 53,8 & 63,6 \\
\hline 600 & 21,9 & 43,2 & 53,5 & 64,6 \\
\hline Regressão & ns & & & \\
\hline Interação $\mathrm{D} \times \mathrm{F}^{(1)}$ & 0,745 & 0,667 & 0,217 & 0,233 \\
\hline $\mathrm{CV}(\%)$ & 6,5 & 6,9 & 9,1 & 6,4 \\
\hline \multicolumn{5}{|c|}{$\begin{array}{l}{ }^{(1)} \text { Interação considerando apenas o fatorial } 2 \text { fontes } \times 3 \text { doses. }{ }^{(2)} \text { Médias seguidas por letras distintas, na coluna } \\
\text { dentro do fator fonte de } \mathrm{N} \text {, diferem entre si pelo teste } \mathrm{F} \text { a } 5 \% \text { de probabilidade, na análise considerando apenas o } \\
\text { fatorial } 2 \text { fontes } \times 3 \text { doses. }{ }^{(3)} y=36,026+0,039810^{* *} x-0,000047^{* *} x^{2} R^{2}=0,91 ;{ }^{(4)} y=41,315+0,071724^{* *} x- \\
0,000086^{* *} x^{2} R^{2}=0,96 ;{ }^{(5)} y=48,574+0,082349 * * x-0,000093^{* *} x^{2} R^{2}=0,97 \text {. ns, }{ }^{*} \text { e }{ }^{* *} \text { são não-significativos e } \\
\text { significativos a } 5 \% \text { e } 1 \% \text { de probabilidade, respectivamente, pelo teste } \mathrm{F} \text {. }\end{array}$} \\
\hline
\end{tabular}

Tais resultados já eram esperados, uma vez que a adubação nitrogenada no cafeeiro é o principal fator responsável pelo crescimento vegetativo da planta (CATANI; MORAES, 1958). Resultados semelhantes dos efeitos da aplicação de $\mathrm{N}$ no crescimento dos ramos dos cafeeiros também foram encontrados por Nazareno et al. (2003) e Parecido (2016).

Entretanto o comprimento do ramo plagiotrópico não foi afetado pela fonte, ou pela interação entre os fatores dose e fonte, nas três avaliações realizadas (Tabela 3). Embora também tenham verificado influência positiva do $\mathrm{N}$ no comprimento dos ramos plagiotrópicos, Lima et al. (2016), também não encontraram diferenças na aplicação de ureia convencional ou revestida.

Em café arábica, as inflorescências são formadas nas axilas das folhas dos ramos plagiotrópicos crescidos no ano anterior, e esses nós produzem flores apenas uma vez. Assim, quanto maior o crescimento dos ramos plagiotrópicos, maior será o potencial produtivo do ano seguinte, pela presença de maior número de nós e, consequentemente, maior número de inflorescências (RENA e MAESTRI, 1986). Dessa forma, os efeitos de maior ou menor crescimento de ramos são fatores muito relevantes na avaliação da eficiência dos tratamentos testados, pois refletem na produção, que é o objetivo final do cultivo. A ausência de diferenças no crescimento dos cafeeiros é de certa forma surpreendente, tendo em vista os conceitos teóricos e os benefícios oferecidos pelas indústrias ao ofertarem a ureia revestida aos agricultores.

Entretanto a ausência de diferenças entre as fontes testadas pode ser justificada devido à ocorrência de precipitações significativas logo após a realização das adubações de cobertura. Para Martins et al. (2014) a ureia do interior das camadas de polímeros se dissolve simultaneamente à ureia convencional caso ambas tenham água disponível por mais de 5 minutos. Dessa forma esse revestimento só teria alguma eficiência se aplicado em solo seco ou com ocorrência de baixa precipitação. Além disso, segundo Silva et al. (1995), há aumento do contato entre o fertilizante e as partículas de solo, com consequente incremento da adsorção de $\mathrm{NH}_{4}{ }^{+}$às cargas negativas do solo, o que dificulta sua transformação a $\mathrm{NH}_{3}$, forma na qual o $N$ é perdido por volatilização. De acordo com Lara Cabezas et al. (1997), se a água for suficiente para diluir a concentração de hidroxilas $\left(\mathrm{OH}^{-}\right)$, ao redor dos grânulos de ureia, que foram produzidos na reação de hidrólise, além de proporcionar a "incorporação" da ureia no solo, há diminuição da volatilização da amônia. Assim, para Maestrelo (2011), precipitações ou 
lâmina de água de irrigação entre 20 à $30 \mathrm{~mm}$ tendem a proporcionar incorporação da ureia, fazendo com que haja diminuição de perdas por volatilização de $\mathrm{N}$ e disponibilizando o $\mathrm{N}$ da ureia convencional semelhantemente à ureia revestida.

\section{CONCLUSÃO}

A adubação nitrogenada influenciou positivamente as características biométricas das plantas de café. Contudo, o fornecimento de $\mathrm{N}$ em cobertura para a cultura do café arábica, através da aplicação de ureia revestida, não apresentou maior eficiência que a aplicação da ureia convencional no comprimento dos ramos e números de nós, nas condições edafoclimáticas do presente estudo.

\section{REFERÊNCIAS BIBLIOGRÁFICAS}

ABRANCHES, Jorge Luiz et al. Ureia revestida por polímeros e a adubação nitrogenada do cafeeiro. X Fórum Ambiental da Alta Paulista, v. 10, n. 7, 2014, pp. 100-112.

BAYER, Cimélio; FONTOURA, Sandra Mara Vieira. Dinâmica do nitrogênio no solo, pré-culturas e o manejo da adubação nitrogenada na cultura do milho em plantio direto. In: FONTOURA, S. M. V.; BAYER, C, (Eds.). Manejo e fertilidade de solos em plantio direto. Guarapuava: Fundação Agrária de Pesquisa Agropecuária; 2006. p. 59-85.

CANTARELLA, Heitor; DUARTE, Aildson Pereira. Manejo da fertilidade do solo para a cultura do milho. In: GALVÃO, J. C. C.; MIRANDA, G. V., eds. Tecnologia de produção de milho. Viçosa, MG, Universidade Federal de Viçosa, p. 139182, 2004.

CEPAGRI. Centro de Pesquisas Meteorológicas Aplicadas a Agricultura. Clima dos municípios paulistas. Disponível em: <http://www.cpa.unicamp.br/outrasinformacoes/clima_muni_068.html>. Acesso em: 13. dez. 2017, 12:02:29.

FENILLI, Tatiele Anete Bergamo. Destino do Nitrogênio (15N) do fertilizante em uma cultura de café. 2006. 100f. Tese (Doutorado) - Centro de Energia Nuclear na Agricultura, Piracicaba, SP, 2006.

GUELFI, Douglas. Fertilizantes nitrogenados estabilizados, de liberação lenta ou controlada. Informações Agronômicas, n. 157, p. 01-14, 2017.

IPMet, Instituto de Pesquisas Meteorológicas de Bauru-SP. Disponível em: <https://www.ipmet.unesp.br/index2.php?menu_esq1=\&abre=ipmet_html/estacao/his torico.php>. Acesso em: 11. jun. 2017, 12:28:20.

LARA CABEZAS, Waldo Alejandro Ruben et al. Volatilização de $\mathrm{NNH}_{3}$ na cultura de milho: I. Efeito da irrigação e substituição parcial da uréia por sulfato de amônio. Revista Brasileira de Ciência do Solo, Viçosa, v. 21, n. 3, p. 481487, 1997.

LARA CABEZAS, Waldo Alejandro Ruben et al. Balanço da adubação nitrogenada sólida e fluida de cobertura na cultura do milho em sistema plantio direto no Triângulo Mineiro. Revista Brasileira de Ciência do Solo, Viçosa, v. 24, n. 2, p. 363-376, 2000.

LIMA, Luara Cristina et al. Crescimento e produtividade do Cafeeiro irrigado, em função de diferentes fontes de nitrogênio. Coffee Science, Lavras, v. 11, n. 1, p. 97 - 107, 2016.

MAESTRELO, Paulo Ricardo. Ureia e ureia revestida por polímeros em milho e feijoeiro de inverno sob sistema de semeadura direta. 2011. 41 f. Trabalho de Conclusão de Curso (Graduação em Agronomia) - Universidade Estadual Paulista, Botucatu, SP, 2011.

MATIELLO, José Braz. Cultura de Café no Brasil: manual de recomendações. Rio de Janeiro: MAPA/PROCAFE, 2010. $542 \mathrm{p}$.

NAZARENO, Rodrigo Barbosa. Crescimento inicial do cafeeiro Rubi em resposta a doses de nitrogênio, fósforo e potássio e a regimes hídricos. Pesquisa Agropecuária Brasileira, Brasília, v. 38, n. 8, p. 903-910, 2003. 
PARECIDO, Renan José. Doses de nitrogênio via solo e aplicação de silício via foliar na cultura do café arábica. 2016. 63 f. Dissertação (Mestre em Agricultura). Universidade Estadual Paulista, Botucatu-SP, 2016.

REIS JÚNIOR, Anjos. Kimcoat N - Uma nova ferramenta para a otimização do uso de fertilizantes. Informações Agronômicas, Chapadão do Sul, n. 117, p. 13-14. 2007.

RENA, Alemar Braga; MAESTRI, Moacyr. Fisiologia do cafeeiro. In: RENA, A. B.; MALAVOLTA, E.; YAMADA, T. (Eds.). Cultura do cafeeiro: fatores que afetam a produtividade. Piracicaba: Potafós, 1986. p.13-85.

SANTOS, Humberto Gonçalves et al. Sistema brasileiro de classificação de solos. 3.ed. Brasília: Empresa Brasileira de Pesquisa Agropecuária, 2013. 353p.

SILVA, Adalberto Jordão et al. Perdas de amônia por volatilização proveniente da ureia aplicada a solos dos trópicos úmidos. Revista Brasileira de Ciência do Solo, Viçosa, v. 19, p. 141-144, 1995.

SILVA, Adriane de Andrade et al. Aplicação de diferentes fontes de ureia de liberação gradual na cultura do milho. Bioscience Journal, Uberlândia, v. 28, Supplement 1, n. 1, p. 104-111, 2012.

VARGAS, Vitor Paulo. Manejo da adubação nitrogenada na recuperação de estresses em milho. 2010. 146f. Dissertação. (Mestrado em Ciência do Solo) Universidade do Estado de Santa Catarina; Lages, SC, 2010.

VILELA, Diego Júnior Martins. Crescimento inicial de cultivares de cafeeiro com diferentes doses de nitrogênio, fósforo e potássio. 2014. 65f. Dissertação. (Mestrado em Produção Vegetal) Universidade Federal de Lavras; Lavras, MG, 2014. 